\title{
EM BUSCA DE EXPERIÊNCIAS: TRANSGREDIR PARA VIVER
}

\author{
Leticia da Silva Santos*
}

\begin{abstract}
RESUMO: este trabalho apresenta uma breve análise do livro Todos os Nomes de José Saramago. A partir do conceito de experiência proposto e desenvolvido pelo doutor em Filosofia da Educação, Jorge Larrosa Bondía, em palestra proferida no $13^{\circ}$ Congresso de Leitura do Brasil (Unicamp, 2001), nos propomos a analisar o trajeto do Sr. José, personagem principal do livro, e acompanhar todas as transgressões por ele cometidas enquanto busca algo bem simples e ao mesmo tempo bem raro: experiências que o façam sentir-se vivo.
\end{abstract}

PALAVRAS-CHAVE: Experiência - Sr. José-Transgressão

\begin{abstract}
Todos os Nomes of José Saramago. From the concept of experience proposed and developed by the Doctor of Philosophy of Education, Jorge Larrosa Bondia,in a seminar in the 13th Congress of Reading in Brazil (Unicamp, 2001), we propose to analyze the passage of Mr. Jose, the central personage of the book, and follow all its trespasses while it searchs something very simple and yet quite rare: the experiences that make it to feel themselves alive.
\end{abstract}

KEYWORDS: Experience-Mr. Jose-Trespass

(...) como foi possível que um auxiliar de escrita como este Sr. José, tão pacífico de seu natural, tão cordato de costumes, tenha sido capaz de conceber, de imaginar, de inventar na sua cabeça, sem dispor de um modelo anterior por onde guiar-se, uma vez que não é norma nem se verificaram necessidades técnicas para que a Conservatória Geral alguma vez tivesse passado credenciais, a expressão de um poder a tal ponto despótico, que é o mínimo que deste se pode dizer. (SARAMAGO, 1997, p. 57)

Em Todos os Nomes, Saramago apresenta-nos o Sr. José, um homem comum como qualquer outro, sem muita importância, mero auxiliar de escrita de uma Conservatória Geral de Registro Civil de uma cidade qualquer. Sua vida resume-se a trabalhar e seguir as rígidas regras impostas por seus superiores. É um homem solitário, modesto, não possui bens materiais, morando numa casa que divide parede com o próprio local de trabalho, sobra do tempo antigo onde as casas dos funcionários eram ligadas à Conservatória com vistas a facilitar o controle da vida deles.

Saramago nos mostra, nesta obra, um mundo que se resume à Conservatória, com suas inúmeras regras, rotinas e hierarquias, e o Sr. José, como um cumpridor exemplar de suas funções. O texto transmite ao leitor a opacidade desse ambiente,

\footnotetext{
* Mestre em Letras pelo Programa de Pós-Graduação em Letras da Universidade Federal do Rio Grande do Sul (PPGLET-UFRGS). E-mail: ticia_santos@yahoo.com.br.
} 
como se a vida fosse sem cor ou como se nem existisse vida, tudo são papéis, nomes, datas, nada mais. Também mostra o quanto esse local é angustiante, um verdadeiro labirinto de papéis, escuro, gigantesco, é um inventário de todas as pessoas existentes, separados apenas em vivos e mortos: os mortos nas prateleiras do fundo do prédio e os vivos mais à frente.

As coisas começam a sair da sua tão rotineira ordem quando o Sr. José, que tinha por mania colecionar recortes de pessoas famosas, percebe que pode melhorar sua coleção conseguindo dados dos registros dessas pessoas arquivados na Conservatória e, para isso, pode utilizar-se da porta de ligação existente entre sua casa e o prédio. Aí começa a primeira transgressão: havia sido proibida a abertura daquela porta.

A inabalável convicção que o chefe da Conservatória Geral alimentava sobre o peso absoluto da sua autoridade, a certeza de que qualquer ordem saída de sua boca seria cumprida com o máximo rigor e o máximo escrúpulo, sem o risco de caprichosas seqüelas ou de arbitrárias derivações por parte do subalterno que a recebesse, foram a causa de que a chave da porta de comunicação se tivesse mantido na posse do Sr. José. Que nunca se lembraria de a usar, que nunca viria a retirá-la da gaveta onde a tinha guardado, se não fosse haver chegado à conclusão de que seus esforços de biógrafo voluntário de pouquíssimo serviriam, objetivamente, sem a inclusão duma prova documental, ou sua cópia fiel, da existência não só real, mas oficial, dos biografados.

Imagine agora quem puder o estado de nervos, a excitação com que o $\mathrm{Sr}$. José abriu pela primeira vez a porta proibida, o calafrio que o fez deter à entrada, como se tivesse posto o pé no limiar duma câmara onde se encontrasse sepultado um deus cujo poder, ao contrário do que é tradicional, não lhe adviesse da ressurreição, mas de tê-la recusado. (SARAMAGO, 1997 , p. 25-26)

Num mundo onde tudo segue uma ordem, como o da Conservatória, onde tudo é regido por regras claras e rígidas, não há porque se temer que algo vá sair do padrão, porém aqui começa a desmoronar tudo isso. Em princípio é tudo muito simples: Não tendo nada o que fazer, o Sr. José procura preencher seu tempo com aquilo, até que, por acaso, numa das noites, vem junto com os registros dos famosos, o registro de uma mulher desconhecida, e isso muda de vez a vida do Sr. José, que faz daquilo uma válvula de escape daquele mundo regrado e parte em busca dessa pessoa, começando uma verdadeira investigação.

Jorge Larrosa Bondía diz, em seu artigo Notas sobre a experiência e o saber da experiência:

\begin{abstract}
A experiência é o que nos passa, o que nos acontece, o que nos toca. Não o que se passa, o que acontece, ou o que toca. A cada dia se passam muitas coisas, porém, ao mesmo tempo, quase nada nos acontece. Dir-se-ia que tudo o que se passa está organizado para que nada se nos passe. (BONDÍA, 2002, p. 21)
\end{abstract}

Mas o que significa tudo isso? Basta olharmos para o mundo do Sr. José e entenderemos. Seu dia-a-dia parece exatamente com o que descreve Larrosa: passam-se muitas coisas, mas nada acontece a ele e com ele. À primeira vista tudo isso parece absurdo, mas olhando com atenção podemos ver que o que o Sr. José busca é sentir-se vivo, é ter uma razão para existir, busca experiência na vida. Não quer ser apenas mais um nome em meio a tantos. Sua vida resume-se a registros. Quer sentir-se atuante na 
vida, protagonista dela e não mero expectador como o era até então. Vemos, através desse gesto, um grito de desespero diante daquele mundo medíocre, regrado e rotineiro do qual faz parte. E como o Sr. José faz para conseguir isso? Deposita suas esperanças naquele registro. Faz dele seu caminho e começa a transgredir suas próprias regras para alcançar o novo objetivo.

(...) tinha o verbete da mulher desconhecida em cima da mesa-de-cabeceira, pus me a olhar para ele como se fosse a primeira vez, Mas já tinha olhado antes, Desde segunda-feira, em casa, quase não fazia outra coisa, Estava portanto a amadurecer a decisão, Ou ela esteve a amadurecer-me a mim, Adiante, adiante, não me venha outra vez com essa, Tornei a calçar os sapatos, vesti o casaco e a gabardina e saí, nem me lembrei de por a gravata (...) Poderia bastar, talvez, se não houvesse no seu relato um pormenor altamente denunciador, incongruente, por assim dizer. Que pormenor, A gravata, Que tem que ver a gravata com esse assunto, Um funcionário da Conservatória Geral do Registro Civil não vai a lado nenhum sem a gravata posta, é impossível, seria uma falta contra a própria natureza. (SARAMAGO, 1997, p. 42-44)

Aqui temos a decisão dele de procurar a mulher e vemos o desencadeamento dessa situação. Tudo começa por uma simples gravata. Simples para nós, mas não para um funcionário da Conservatória. Logo após, ele começa a mentir. Mente quando é questionado pelos superiores, mente para a moradora do apartamento onde a mulher desconhecida havia nascido e, a cada nova transgressão, ele parece sentir-se mais vivo, mais real. Não é mais um no meio da multidão. Não é um robô sem vontades próprias, arrisca-se para vivenciar experiências. Pensa por conta própria, toma decisões, embora insensatas e impensadas, mas faz tudo isso sem estar seguindo ordens e isso o faz diferente de todo o seu mundo.

Surgem os primeiros medos, pois, se de um lado, é gostoso e apaixonante sentirse vivo, de outro, essa nova vida traz medos que seu pacato mundo de antes não possuía: medo de ser apanhado, medo de ser descoberto, mas o maior medo, a maior angústia é de que tudo aquilo acabe.

Despertou-o uma ideia inesperada que lhe irrompeu no meio do sono, de um modo tão fulminante que nem deu tempo que um sonho se tecesse com ela, a idéia de que talvez a mulher desconhecida, a do verbete, fosse, afinal de contas, aquela que ele ouvira embalar a criança, a do marido impaciente, nesse caso a sua busca teria terminado, estupidamente terminado, no próprio momento em que deveria começar. Uma angústia súbita apertou-lhe a garganta enquanto a razão afligida tentava resistir, queria que ele mostrasse indiferença, que dissesse, Melhor assim, menos trabalho me dará, mas a angústia não desistia, continuava a apertar, a apertar, e agora era ela que estava a perguntar à razão, E que vai ele fazer, se já não pode realizar o que pensou, Fará o que sempre fez, recortará recortes de jornais, fotografias, notícias, entrevistas, como se não tivesse sucedido nada. Coitado, não acredito que o consiga, Porquê, A angústia, quando chega não se vai embora com essa facilidade, Poderá escolher outro verbete e ir à procura dessa pessoa, $\mathrm{O}$ acaso não escolhe, propõe, foi o acaso que lhe trouxe a mulher desconhecida, só ao acaso compete ter voto nesta matéria. (ibid., p. 47)

Ele não quer voltar ao antigo vazio existencial, às simples rotinas de antes. $\mathrm{O}$ desespero toma conta de todo o seu ser, impedindo-o de dormir a noite toda. No dia seguinte, pede permissão para sair do serviço mais cedo. Vinte cinco anos como 
funcionário e jamais fizera isso! Que façanha para ele! E tudo isso em nome daquela busca, da busca que o faz sentir-se livre, vivo e com forças para quebrar todos os padrões firmemente construídos até aqui.

O Sr. José fala com a madrinha da sua mulher desconhecida, a senhora do rêsdo-chão direito, que lhe conta onde estudava sua afilhada e, ao final do diálogo, pergunta a ele porque não procurara na lista telefônica.

Por quê? Aí está uma grande pergunta, mas nós temos a resposta. O Sr. José não estava querendo achá-la assim, rápido. O que ele quer é essa busca, quer se sentir participante de uma aventura. Não é um simples encontrá-la, é um encontrar diferenciado. Larrosa Bondía diz:

A experiência, a possibilidade de que algo nos aconteça ou nos toque, requer um gesto de interrupção, um gesto que é quase impossível nos tempos que correm: requer parar para pensar, parar para olhar, parar para escutar, pensar mais devagar, olhar mais devagar, parar para sentir, sentir mais devagar, demorar-se nos detalhes, suspender a opinião, suspender o juízo, suspender a vontade, suspender o automatismo da ação, cultivar a atenção e a delicadeza, abrir os olhos e os ouvidos, falar sobre o que nos acontece, aprender a lentidão, escutar aos outros, cultivar a arte do encontro, calar muito, ter paciência e dar-se tempo e espaço. (BONDÍA, 2002, p. 24)

E o Sr. José se lança com todas as forças nessa busca, cometendo todas as transgressões necessárias, usando seus sentidos ao máximo, experimentando todas as novas sensações. Com posse do endereço do colégio onde estudara a mulher, resolve invadi-lo e faz isso sem pestanejar. Sobe ao telhado numa noite chuvosa, quebra uma janela e entra em busca de mais revelações a respeito de seu enigma. Supera seu nervosismo e seu medo de altura, deixa de lado toda a racionalidade do homem da sua época e sai agindo por impulsos, como se tudo fosse justificado pela sua busca.

O resultado dessa última aventura é uma bela gripe. Ele abre a porta de ligação entre a Conservatória e a sua casa pela manhã e comunica ao subchefe que não irá trabalhar por estar com febre. Mais regras quebradas: abrir a porta de comunicação e expor-se aos olhos de todos de pijamas; avisar que não irá trabalhar. Totalmente absurdo para o mundo regrado da Conservatória. Mas sua atitude não foi mais surpreendente que a do seu chefe:

O subchefe vinha aí para lhe dizer que hoje ou amanhã seria visitado pelo médico oficial, mas logo a seguir, ó maravilha, pronunciou umas palavras que nenhum funcionário inferior da Conservatória Geral, ele ou outro qualquer, tivera a felicidade de escutar alguma vez, O chefe deseja-lhe as melhoras, e o próprio subchefe não parecia acreditar no que estava a dizer. (SARAMAGO, 1997, p. 116)

Aqui vemos as coisas mudarem: as loucas atitudes do Sr. José acabam por desencadear desarranjos na estrutura normal do seu mundo. Como se, ao sair de seu lugar habitual, provocasse um desmoronamento. Assim como um parafuso faz falta num aparelho e provoca reações adversas em seu funcionamento, desregulando-o, assim o Sr. José provoca uma revolução na Conservatória. Sua mudança influencia seu local de trabalho.

O sujeito da experiência se define não por sua atividade, mas por sua passividade, por sua receptividade, por sua disponibilidade, por sua abertura. 
Trata-se, porém, de uma passividade anterior à oposição entre o ativo e o passivo, de uma passividade feita de paixão, padecimento, de paciência, de atenção, como uma receptividade primeira, como uma disponibilidade fundamental, como uma abertura essencial. (BONDÍA, 2002, p. 24)

Segundo Larrosa Bondía, o sujeito tem de estar aberto para "sofrer" a experiência. Vemos aqui não só o Sr. José aberto a experiências, mas também seu chefe que começa transgredindo ordens de hierarquia para dar um cuidado especial a um simples funcionário. Depois de melhorar da doença, o Sr. José retorna ao trabalho e é novamente surpreendido ao ver o interesse do chefe em saber do seu estado de saúde e a proposta de alguns dias de férias para se restabelecer por completo.

O Sr. José continua suas buscas com os dados obtidos no colégio, mas não vai muito longe. A mulher desconhecida não mora mais no endereço escrito nas fichas escolares. E o Sr. José novamente sente-se sem chão.

\begin{abstract}
O imaginário e metafísico diálogo com o tecto servira-lhe para encobrir a total desorientação do seu espírito, a sensação de pânico que lhe vinha da ideia de que já não teria mais nada para fazer na vida, se, como havia razões para recear, a busca da mulher desconhecida havia terminado. Sentia um nó duro na garganta, como quando lhe ralhavam em criança e queriam que ele chorasse, e ele resistia, até que por fim as lágrimas saltavam, como também começaram a saltar agora por fim. (SARAMAGO, 1997, p. 159)
\end{abstract}

Diante das ameaças de um final sem sucesso, de seus objetivos sem alcance, o Sr. José chora copiosamente. Ele vive todos aqueles sentimentos intensamente, sejam de dor como agora, sejam de medo diante do Conservador, sejam de alegria e satisfação ao descobrir novas pistas. Ele vive intensamente sua busca. Larrosa Bondía diz:

Do ponto de vista da experiência, (...) o importante é a exposição, nossa maneira de expormos, com tudo o que isso tem de vulnerabilidade e de risco. (...) O sujeito da experiência tem algo desse ser fascinante que se expõe atravessando um espaço indeterminado e perigoso, pondo-se nele à prova e buscando nele sua oportunidade, sua ocasião. (BONDÍA, 2002, p. 25)

Ao retornar ao trabalho, nova surpresa espera o Sr. José. Chega um verbete para que ele faça uma transcrição: uma mulher com o nome quase todo igual ao da sua mulher desconhecida. Ele aproveita para olhar no arquivo seu verbete, mas não o encontra. Só há uma justificativa para isso: a mulher desconhecida está morta. Sua busca imediata é pelos registros no arquivo dos mortos. Precisa saber como isso aconteceu. Durante a noite, ele penetra pelos labirintos do mundo dos mortos em busca de sua mulher desconhecida. Enfrenta seu pavor daquele lugar e retorna com o processo dela. Só que há algo faltando nele: não há a causa da morte, tal folha deve ter caído no meio da escuridão.

Totalmente desnorteado, o Sr. José resolve ir ao encontro da senhora do rês-dochão direito contar a ela aquilo tudo: vai revelar a verdade afinal. Revela toda sua história e ela sugere que continue a busca para concluir suas investigações ou que comece uma nova, dessa vez da morte para a vida da mulher desconhecida. Larrosa Bondía diz: 
mesma, mas numa aceitação primeira de algo que está fora de mim, de algo que não sou eu e que por isso, justamente, é capaz de me apaixonar (...) O que o sujeito ama é precisamente sua própria paixão. Mais ainda: o sujeito não é outra coisa e não quer ser outra coisa que não a paixão. Daí talvez a tensão que a paixão extrema suporta entre a vida e a morte. A paixão tem uma relação intrínseca com a morte, mas de uma morte que é querida e desejada como verdadeira vida, como a única coisa que vale a pena viver, e às vezes como condição de possibilidade de todo o renascimento. (BONDÍA, 2002, p. 26)

O Sr. José não para ao descobrir que sua mulher desconhecida morreu. Como Larrosa Bondía diz, "o sujeito ama a sua própria paixão" (BONDÍA, 2002, p. 26), é exatamente o que ocorre com ele. Não é a mulher em si, mas a busca é o que importa, os sentimentos e sensações vividas e experimentadas que dão razão a tudo aquilo.

Nesse meio tempo, o Conservador chama todos os funcionários para dizer algumas palavras e faz um discurso sobre a mudança das coisas no decorrer do tempo, acrescentando que ele continuaria sem mudar se novas reflexões não viessem a apontar a necessidade de novos caminhos e conclui ordenando:

Farei baixar, portanto, uma ordem de serviço em que se especificará, primeiro, que a partir desta data os mortos permanecerão no mesmo lugar do arquivo que tinham ocupado em vida, segundo, que progressivamente, processo a processo, documento a documento, dos mais recentes aos mais antigos, se procederá à reintegração dos mortos do passado no arquivo que passará a ser o presente de todos (...) Assim como a morte definitiva é o fruto último da vontade de esquecimento, assim a vontade de lembrança poderá perpetuar-nos a vida. (SARAMAGO, 1997, p. 209)

O Conservador, em contato com todas as transgressões do Sr. José e, influenciado por elas, se permitiu experienciar algo, teve uma abertura - como diz Larrosa - e conseguiu transformar-se e transformar suas atitudes diante de um mundo rápido e sem tempo para isso.

Nosso personagem continua sua busca. Vai ao cemitério em busca da sepultura de sua mulher desconhecida e descobre que ela havia cometido suicídio. Procura o local onde a mulher fora enterrada e passa a noite no gigantesco labirinto que é o local.

Está aqui, ficou sem saber o que havia de fazer mais. Era certo que, ao cabo de muitos e custosos trabalhos, tinha conseguido, finalmente, encontrar a mulher desconhecida, ou melhor dizendo, o lugar onde ela jazia, (...) mas o que percebia dentro de si parecia-se muito mais com uma indecisão, com uma dúvida, como se, crendo ter chegado ao fim de tudo, a sua busca ainda não tivesse terminado, como se ter aqui vindo não representasse senão um ponto de passagem, sem mais importância que a casa da senhora idosa do rês-do-chão direito, ou o colégio, ou a farmácia aonde tinha ido fazer perguntas, ou o arquivo em que, lá na Conservatória, se guardavam os papéis dos mortos. (ibid., p. 233)

Pela manhã fica sabendo que o local onde ele está a observar não é o correto. Há um pastor de ovelhas que troca os números das sepulturas daqueles que tiraram suas vidas. Sua mulher desconhecida acaba de desaparecer novamente. A busca enfim não está terminada. Ele procura os pais dela, descobre que havia se tornado professora na mesma escola onde fora aluna e obtém a chave do apartamento onde ela estava morando até sua morte. 
O Sr. José resolve, portanto, dar continuidade a sua busca e comete mais uma transgressão. E desta vez não é pequena para um auxiliar de escrita como ele: resolve faltar o serviço na segunda-feira para ir à escola dela pedir documentos em nome da Conservatória, no que é prontamente atendido. Após esse fato, dirige-se até o apartamento da mulher desconhecida para vasculhar o resto dos mistérios. Ao retornar a sua casa, encontra o Conservador esperando-o. Ele havia descoberto tudo e acompanhava as ações do Sr. José lendo suas anotações, uma espécie de diário que ele criara para colocar todos os passos da investigação. Mas ao invés de ser demitido como pensava, o conservador faz-se cúmplice dele e sugere:

Sabe qual a única conclusão lógica de tudo o que sucedeu até o momento, Não senhor, Fazer para esta mulher um verbete novo, igual ao antigo, com todos os dados certos, mas sem a data do falecimento, E depois, Depôs colocá-lo no ficheiro dos vivos, como se ela não tivesse morrido, Seria uma fraude, Sim, seria uma fraude, mas nada do que temos feito e dito, o senhor e eu, teria sentido se não a cometêssemos (...) Há ainda uma última questão a resolver, Qual, senhor, No processo da sua mulher desconhecida falta o certificado do óbito, Não consegui descobri-lo, deve ter ficado lá no fundo do arquivo, ou então deixei-o cair pelo caminho, Enquanto não o encontrar essa mulher estará morta, Estará morta mesmo que o encontre, A não ser que o destrua. (SARAMAGO, 1997, p. 278)

E o Sr. José parte em busca do certificado para destruí-lo. A busca continua e sua mulher desconhecida passa a ser imortal. Quanto ao Sr. José, podemos concluir com as palavras de Larrosa Bondía:

A experiência é a passagem da existência, a passagem de um ser que não tem essência ou razão ou fundamento, mas que simplesmente 'ex-iste' de uma forma sempre singular, finita, imanente, contingente. (...) Posto que não se pode antecipar o resultado, a experiência não é o caminho até um objetivo previsto, até uma meta que se conhece de antemão, mas é uma abertura para o desconhecido, para o que não se pode antecipar nem 'pré-ver' nem 'prédizer'. (BONDÍA, 2002, p. 28)

\section{REFERÊNCIAS}

BONDÍA, Jorge Larrosa. Notas sobre a experiência e o saber da experiência. Revista Brasileira de Educação nº19, 2002.

SARAMAGO, José. Todos os Nomes. São Paulo: Companhia das Letras, 1997. 